\title{
GENE DA PUTATIVA INDOLPIRUVATO DESCARBOXILASE DE Phytomonas: \\ CARACTERIZAÇÃO, ARRANJO GENÔMICO, MARCADOR MOLECULAR E ORIGEM FILOGENÉTICA
}

Dissertação apresentada ao Programa de PósGraduação em Parasitologia do Instituto de Ciências Biomédicas da Universidade de São Paulo, para a obtenção do Título de Mestre em Ciências Biológicas.

Área de Concentração: Biologia da Relação Patógeno-Hospedeiro

Orientadora: Profa. Dra. Bianca S. Zingales 


\section{RESUMO}

lenne da Silva, S. Gene da Putativa Indolpiruvato Descarboxilase de Phytomonas: Caracterização, Arranjo Genômico, Marcador Molecular e Origem Filogenética. 2007. 114 f. Dissertação (Mestrado em Parasitologia) - Instituto de Ciências Biomédicas, Universidade de São Paulo, São Paulo, 2007.

O gênero Phytomonas está associado a enfermidades devastadoras em plantações de interesse econômico, enquanto que em outros vegetais parasitados não promove nenhum dano aparente. A seqüência-consenso de um agrupamento de ESTs de $P$. serpens determinado anteriormente apresentou os maiores índices de similaridade (BLAST X) com indolpiruvato descarboxilases (IPDCs) de fitobactérias e com putativas piruvato/indolpiruvato descarboxilases de Leishmania spp. A enzima IPDC está na via de biossíntese do ácido 3indolil acético, um dos hormônios vegetais mais importantes. Bactérias cujos genes codificam para enzimas que levam à síntese deste fitormônio são patogênicas para plantas ou podem ser benéficas a elas. A coincidência de encontrar o gene IPDC em um tripanossomatídeo de plantas e em fitobactérias sugere um processo de transferência horizontal gênica. O presente trabalho tem por objetivo caracterizar o gene da putativa IPDC em $P$. serpens, determinar a presença do gene em isolados de Phytomonas e em outras espécies de tripanossomatídeos, analisar o arranjo genômico e investigar a origem do gene por inferências filogenéticas. A seqüência do gene da putativa IPDC de $P$. serpens apresenta domínios para Tiamina Pirofosfato (TPP), típicos de descarboxilases. Ensaios de PCR mostram que o gene está presente em todos os isolados de Phytomonas analisados e sugerem que sua seqüência seja bastante conservada. Por outro lado, estes ensaios indicam que a seqüência está ausente em outras espécies de Kinetoplastida (Trypanosoma, Leishmania, Endotrypanum, Crithidia, Blastocrithidia, Herpetomonas e Leptomonas), o que sugere que a seqüência de IPDC poderia ser um marcador potencial para o gênero Phytomonas. Conclui-se que o gene está presente em múltiplas cópias (cerca de $10^{4}$ cópias em $P$. serpens), organizadas em tandem e separadas por uma região intergênica pequena. As cópias estão concentradas em uma banda cromossômica de aproximadamente 2,1 Mpb. Em $P$. serpens, a seqüência telomérica difere da seqüência conservada em $T$. brucei e $T$. cruzi. Em $P$. françai o número de cópias do gene IPDC é menor (cerca de 200 cópias). As análises filogenéticas apontam o clado Phytomonas (putativa IPDC) - Leishmania (putativa piruvato/indolpiruvato descarboxilase) como grupo-irmão das IPDCs das gamaproteobactérias Pantoea agglomerans, Enterobacter cloacae, Pseudomonas putida e Erwinia carotovora, sugerindo um processo de transferência horizontal gênica anterior à separação de Phytomonas e Leishmania. Resultados de amplificações por PCR com oligonucleotídeos degenerados reforçam a idéia de que a aquisição desse gene putativo, 
advindo de um provável ancestral bacteriano, seja anterior à separação dos tripanossomatídeos do clado que inclui Leptomonas, Phytomonas, Herpetomonas, Leishmania e Crithidia.

Palavras-chave: Phytomonas. Indolpiruvato Descarboxilase. Transferência Horizontal Gênica. Ácido 3-indolil acético. 
lenne da Silva, S. Gene of the Putative Indolepyruvate Decarboxylase of Phytomonas: Characterization, Genomic Arrangement, Molecular Marker and Phylogenetic Origin. 2007. 114 f. Master thesis (Parasitology) - Instituto de Ciências Biomédicas, Universidade de São Paulo, São Paulo, 2007.

The genus Phytomonas is associated to devastating diseases in commercially important crops, whereas in other plant species no apparent damage is observed. The consensus sequence of one group of ESTs of $P$. serpens previously determined showed the highest similarity hits (BLAST $X$ ) with indolepyruvate decarboxylases (IPDCs) from phytobacteria and putative pyruvate/indolepyruvate decarboxylases of Leishmania spp. The enzyme IPDC participates in the biosynthetic pathway of the indole-3-acetic acid, one of the most important plant hormones. Bacteria that synthesize this phytohormone are pathogenic to plants or can be beneficial to them. The coincidence of finding the IPDC gene in the plant trypanosomatid and in phytobacteria suggests a process of horizontal gene transfer. The goals of this study are to characterize the putative IPDC gene of $P$. serpens; determine the presence of this gene in Phytomonas isolates and other trypanosomatid species; analyze the genomic arrangement and investigate the gene origin by phylogenetic inferences. The $P$. serpens gene sequence contains Thiamine Diphosphate (ThDP) domains, typical of decarboxylases. PCR assays show that the gene is present in all Phytomonas isolates analyzed and suggest that this sequence is well conserved. On the other hand, these assays indicate that this sequence is absent in other Kinetoplastida species (Trypanosoma, Leishmania, Endotrypanum, Crithidia, Blastocrithidia, Herpetomonas and Leptomonas). This suggests that the IPDC sequence could be a potential marker for the genus Phytomonas. It is concluded that the gene is present in multiple copies (about $10^{4}$ copies in $P$. serpens), organized in tandem and separated by a small intergenic region. Gene copies are concentrated in a chromosomal band of approximately $2.1 \mathrm{Mbp}$. In $P$. serpens the telomeric sequence differs from the conserved sequence in $T$. brucei and $T$. cruzi. In $P$. françai the copy number of the IPDC gene is lower (about 200 copies). The phylogenetic analyses point the clade Phytomonas (putative IPDC) - Leishmania (putative pyruvate/indolepyruvate decarboxylase) as a sister group of a clade clustering IPDCs of the phytobacteria Pantoea agglomerans, Enterobacter cloacae, Pseudomonas putida and Erwinia carotovora, suggesting a process of horizontal gene transfer prior to the separation of Phytomonas and Leishmania. Data of PCR amplifications with degenerated primers support the idea that the acquisition of this putative gene from a likely bacterial ancestor happened prior to the separation of the trypanosomatid clade that includes Leptomonas, Phytomonas, Herpetomonas, Leishmania and Crithidia. 
Key words: Phytomonas. Indolepyruvate decarboxylase. Horizontal Gene Transfer. Indole3-acetic acid 


\section{INTRODUÇÃO}

\section{10 gênero Phytomonas}

A descoberta de protozoários da família Trypanosomatidae parasitando vegetais ocorreu em 1909, com a identificação de um parasita de látex de Euphorbia pilulifera, denominado por Lafont como Leptomonas davidi (JANKEVICIUS et al., 1988). No mesmo ano, Donovan propôs o nome Phytomonas como nome genérico para tripanossomatídeos parasitas de vegetais (JANKEVICIUS et al., 1988), porém, a terminologia passou a ganhar aceitação apenas 70 anos mais tarde. Até então os flagelados de plantas eram referidos como pertencentes aos gêneros Leptomonas e Herpetomonas, e até mesmo Trypanosoma (CAMARGO, 1999).

A definição de Phytomonas dada por Donovan era claramente artificial, uma vez que outros Kinetoplastida, tais como Leptomonas, Crithidia e Herpetomonas, podem estar presentes em vetores e em infecções transitórias em plantas, e a distinção entre Phytomonas e esses organismos é difícil devido à sua plasticidade morfológica (Figura 1). Apesar de isolados de Phytomonas apresentarem algumas peculiaridades verificadas ao microscópio de transmissão eletrônica, como arranjo especial de ribossomos, cisternas endoplasmáticas e presença de corpos elétrondensos no citoplasma, essas peculiaridades não são suficientes para diagnosticar um parasita como pertencente ao gênero Phytomonas (CAMARGO, 1999). Logo, os critérios de hospedeiro de origem e de morfo-desenvolvimento não permitiam a correta distinção do gênero Phytomonas de outros tripanossomatídeos, e somente recentemente marcadores moleculares tornaram-se disponíveis para auxiliar na identificação do gênero (CAMARGO, 1999). 


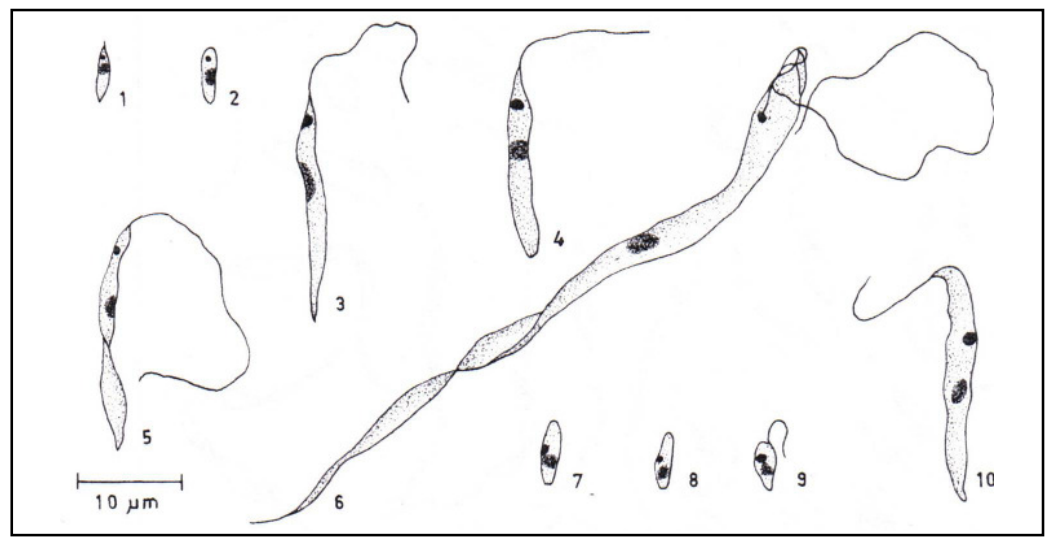

Figura 1. Polimorfismo de Phytomonas serpens, parasita de tomate: 1 e 2, formas de seiva do fruto; 3 e 4, flagelados de meio bifásico ágar-sangue/LIT; 5 e 6, formas alongadas de fase estacionária de meio de cultura LIT; 7 e 8 , formas nãoflageladas de urina de vetores hemípteros; 9 e 10, flagelados do trato digestivo de vetor. (Retirado de: CAMARGO, 1999; modificado de JANKEVICIUS et al., 1989)

Foi chamada a atenção para o gênero Phytomonas quando se verificou que estes organismos causavam enfermidades devastadoras em plantações de interesse econômico, principalmente na América Latina (DOLLET, 1984), tais como mandioca ("chochamento das raízes"), café (necrose do floema), coco ("hartrof") e palmeiras produtoras de óleo ("marchitez sorpressiva"). Por outro lado, foi verificado que outros vegetais infectados por Phytomonas, tais como tomate e batata, não apresentavam nenhum dano aparente (MCGHEE e COSGROVE, 1980; SÁNCHEZ-MORENO et al., 1995; CAMARGO, KASTELEIN e ROITMAN, 1990; CAMARGO, 1999). Esta diferença intrigante foi relacionada com o tipo de distribuição do organismo nos tecidos do hospedeiro, como veremos a seguir. De acordo com sua distribuição, os tripanossomatídeos que infectam plantas são classificados em:

- lactícolas, presentes no látex de várias plantas, especialmente de Euphorbiaceae e Asclepiadaceae (CAMARGO, KASTELEIN e ROITMAN, 1990; DOLLET, 1984). Nestes vegetais, os isolados não são patogênicos, com exceção de $P$. françai, encontrada em mandioca (Manihot esculenta) (KITAJIMA, VAINSTEIN e SILVEIRA, 1986; VAINSTEIN e ROITMAN, 1986; MIRANDA et al., 2004);

- frutícolas, encontrados na polpa e nas sementes de frutos de diversas famílias. Não se sabe se são parasitas dos frutos ou apenas invasores oportunistas, pois, na maioria dos frutos, apenas poucos flagelados podem ser detectados (JANKEVICIUS et al., 1989; CAMARGO et al., 1990; VICKERMAN, 1994). Uma exceção é $P$. 
serpens, extremamente abundante em tomates, sem, no entanto, promover patogênese (JANKEVICIUS et al., 1989; CAMARGO et al., 1990);

- floemícolas, presentes no floema de plantas não lactíferas; como coco, café e palmeiras produtoras de óleo. Os isolados são patogênicos, causando murchamento/definhamento (necrose do floema) (DOLLET, 1984; VICKERMAN, 1994; CAMARGO, 1999); e

- florícolas, descritos em poucas espécies vegetais (CAMARGO, 1999).

Em resumo, apenas Phytomonas encontradas no floema estariam associadas com uma patogênese severa (CAMARGO, KASTELEIN e ROITMAN, 1990; VICKERMAN, 1994; UTTARO, SÁNCHEZ-MORENO e OPPERDOES, 1997; CAMARGO, 1999; DOLLET, STURM e CAMPBELL, 2001). Ainda assim, a classificação conforme o tecido do hospedeiro parece um pouco prematura, de acordo com os dados bioquímicos de caracterização desses tripanossomatídeos (DOLLET, 1984).

No final da década de 80, anticorpos monoclonais foram desenvolvidos na tentativa de distinguir espécies de Phytomonas de outros tripanossomatídeos, porém, nem todas as espécies de Phytomonas reagiam igualmente com os anticorpos testados (PETRY et al., 1989; TEIXEIRA e CAMARGO, 1989). Em 1996, o grupo de Teixeira desenvolveu um teste para confirmar a real existência do gênero através da hibridização de DNA com uma sonda específica (SL3') complementar à seqüência do mini-exon ou gene spliced leader (TEIXEIRA et al., 1996) e, três anos mais tarde, o mesmo grupo desenvolveu uma PCR baseada em regiões que flanqueiam a seqüência SL3', amplificando um fragmento de DNA específico de Phytomonas, facilitando o diagnóstico do gênero (SERRANO et al., 1999; CAMARGO, 1999). Por outro lado, nenhum critério objetivo foi estabelecido para a definição de espécies dentro do gênero ou para identificação de populações (MARCHÉ et al., 1995; DOLLET, STURM e CAMPBELL, 2001).

Algumas particularidades do metabolismo de Phytomonas foram estudadas em maior detalhe. Dentre elas, o aspecto mais marcante foi a observação de que vários genes da cadeia respiratória estão ausentes do genoma do cinetoplasto (NAWATHEAN e MASLOV, 2000; GONZÁLEZ-HALPHEN e MASLOV, 2004). Também foi relatado que a produção de ATP deriva principalmente da glicólise, tendo em vista que o ciclo de Krebs aparentemente não é funcional (SÁNCHEZMORENO et al., 1992). Este tipo de adaptação é condizente com a sobrevivência do 
organismo no meio rico em carboidratos do hospedeiro vegetal e com a concentração elevada de glicosomas no citoplasma, quando comparado com outros tripanossomatídeos (SÁNCHEZ-MORENO et al., 1992; CAMARGO, 1999). Pouco se conhece sobre o metabolismo de Phytomonas nos insetos vetores, que pertencem à ordem Hemíptera (sendo os insetos das famílias Coreidae, Pentatomidae e Lygaeidae os principais suspeitos de serem vetores de Phytomonas) (DOLLET, 1984; SBRAVATE et al., 1989), mas postula-se que os aminoácidos seriam a principal fonte de energia (MOLINAS et al., 2003; GONZÁLEZ-HALPHEN e MASLOV, 2004). O conhecimento de uma série de características da biologia deste organismo é dificultado por problemas na obtenção de formas evolutivas puras in vitro (CAMARGO, 1999). Assim, quando comparado com outros tripanossomatídeos, há falta de informação no que se refere a aspectos do ciclo celular, transmissão, patogenicidade, tratamento e profilaxia.

Nos últimos anos, vários projetos de seqüenciamento foram iniciados em tripanossomatídeos, culminando com o seqüenciamento do genoma de Trypanosoma cruzi, T. brucei e Leishmania major em 2005 (EL-SAYED et al., 2005a; BERRIMAN et al., 2005; IVENS et al., 2005). As Etiquetas de Seqüências Transcritas (ESTs), depositadas em bancos de dados, fornecem informações valiosas, sendo usadas para expandir o conhecimento básico, revelar produtos gênicos desconhecidos e identificar marcadores moleculares úteis para tipagem.

Até $\mathrm{o}$ ano de 2004, os estudos de biologia molecular em fitoflagelados visavam basicamente a taxonomia e o diagnóstico (HOLLAR e MASLOV, 1997; SERRANO et al., 1999). Desta forma, foram caracterizados predominantemente genes de múltiplas cópias, tais como a seqüência líder (TEIXEIRA et al., 1996; SERRANO et al., 1999; DOLLET et al., 2001), genes de RNA ribossômico (DOLLET et al., 2000) e os minicírculos do kDNA (DOLLET, STURM e CAMPBELL, 2001). Para Phytomonas spp. muito poucos genes haviam sido caracterizados até o início do ano de 2005.

\section{2 Indolpiruvato Descarboxilase}

Recentemente nosso grupo, em colaboração com o grupo do Dr. Antonio Gonzalez (Instituto de Parasitología y Biomedicina, CSIC, Granada, Espanha) e do Dr. Georgios Pappas Júnior (Universidade Católica de Brasília, UCB, Brasil), gerou, 
seqüenciou e analisou com ferramentas de bioinformática 2.190 ESTs de uma biblioteca de cDNA de $P$. serpens (PAPPAS et al., 2005). Após a formação de agrupamentos, as categorias funcionais das seqüências-consenso foram designadas por buscas com o programa BLAST contra o banco de dados KOG. Cerca de $36 \%$ das seqüências não apresentaram precedentes, ao passo que 39,6\% apresentaram similaridade com classes de proteínas implicadas em processos de tradução, biogênese e estrutura ribossômica. $O$ agrupamento mais populoso de $P$. serpens continha ESTs homólogas a membros da família de transportadores de glicose. Este achado pode ser diretamente correlacionado com a dependência de Phytomonas da produção de ATP a partir da glicólise, conforme descrito acima. Foram identificadas várias enzimas da via glicolítica, mas também do Ciclo de Krebs e da cadeia respiratória (PAPPAS et al., 2005). Esse estudo contribuirá para responder questões importantes referentes ao metabolismo, interação organismo-hospedeiro e sistemática molecular do gênero Phytomonas.

A seqüência-consenso (540 nucleotídeos) de um dos agrupamentos de ESTs de $P$. serpens apresentou os maiores índices de similaridade pelo programa BLAST $X$ (versão 2.2.14) (ALTSCHUL et al., 1997) com indolpiruvato descarboxilases (IPDCs) (EC 4.1.1.74) de fitobactérias, piruvato descarboxilases (PDCs) (EC 4.1.1.1) e com uma putativa piruvato/indolpiruvato carboxilase de $L$. major.

A seqüência completa do gene da putativa IPDC de $P$. serpens, representada por $2.364 \mathrm{pb}$, sendo $1.647 \mathrm{pb}$ correspondentes à fase aberta de leitura (ORF), foi obtida por nosso colaborador Dr. A. Gonzalez (Granada, Espanha) (dados não publicados). A busca pelo programa BLAST X no banco de dados $n r$ (non redundant) do NCBI utilizando como entrada (query) a seqüência nucleotídica completa (2.364 pb) confirma a elevada similaridade com IPDCs e PDCs. Ambas classes de descarboxilases apresentam sítios de ligação para a coenzima Tiamina Pirofosfato (TPP). As três primeiras entradas correspondem às putativas piruvato/indolpiruvato carboxilases de L. braziliensis, L. major e L. infantum. Esta anotação deve ser vista com reservas pois, muito provavelmente, as seqüências foram geradas automaticamente em decorrência do projeto Genoma. A reação catalisada pela IPDC é irreversível (ácido 3-indol pirúvico $\rightarrow$ 3-indol acetaldeído $+\mathrm{CO}_{2}$ ) (ver Fig. 4 adiante), assim como é irreversível a reação catalisada pela piruvato descarboxilase (piruvato $\rightarrow$ acetaldeído $+\mathrm{CO}_{2}$ ). Desta forma, não existe uma indolpiruvato carboxilase (reação inversa). Sabe-se que a piruvato carboxilase utiliza como 
coenzima a Biotina. Fazendo uma análise dos domínios dessas putativas enzimas de Leishmania com o programa PFAM (BATEMAN et al., 2004) (site: http://www.sanger.ac.uk/ Software/Pfam/search.shtml), observamos a presença de domínios para TPP, indicando tratarem-se de descarboxilases e não de carboxilases, como anotado. Outro ponto que chama a atenção foi não termos encontrado genes ortólogos para a putativa piruvato/indolpiruvato carboxilase nos genomas de $T$. cruzi e $T$. brucei, ao contrário do que ocorre para muitos genes que são conservados nas três espécies de tripanossomatídeos (EL-SAYED et al., 2005b).

A quarta entrada do BLAST X com maior similaridade tanto com a seqüência consenso de 540 nt quanto com a seqüência nucleotídica completa de $P$. serpens foi obtida com a IPDC da bactéria Pantoea agglomerans, também conhecida como Erwinia herbicola (sinônimo heterotípico). Esta bactéria é comumente encontrada na superfície de plantas (BRANDL, CLARK e LINDOW, 1996; BRANDL, QUIÑONES e LINDOW, 2001; BRANDL e LINDOW, 1997, 1998).

$O$ fato de o gene da putativa IPDC de Phytomonas apresentar elevada similaridade com IPDCs de fitobactérias sugere que este gene poderia ter sido adquirido por transferência horizontal. A hipótese de transferência horizontal gênica (HTG, Horizontal Gene Transfer) já havia sido levantada anteriormente para a aquisição do gene de $P$. serpens que codifica para uma isopropil álcool desidrogenase multifuncional (iPDH) (MOLINAS et al., 2003). De fato, em vários isolados de Phytomonas foi descrito que acetaldeído pode ser reduzido por $\mathrm{PPDH}$ regenerando parte do poder oxidativo necessário para a glicólise (MOLINAS et al., 2003) e que essa atividade está ausente em outras espécies de tripanossomatídeos (UTTARO, SÁNCHEZ-MORENO e OPPERDOES, 1997). Foi verificado que a seqüência do gene de iPDH de Phytomonas comportava-se de forma monofilética com álcool desidrogenases de Mycoplasma penetrans e de várias Proteobactérias, o que sugeriria que o gene iPDH teria sido adquirido por HTG (MOLINAS et al., 2003).

A enzima IPDC está na via de biossíntese do ácido 3-indolil acético (auxina, AIA) (Figura 2), um dos hormônios vegetais mais importantes. A auxina desempenha papel fundamental nos processos de formação de raiz e divisão celular, promovendo $o$ alongamento do caule e inibindo o alongamento da raiz. Atua ainda na dominância apical, abscisão foliar e desenvolvimento de fruto partenocárpico (PURVES et al., 2002). 


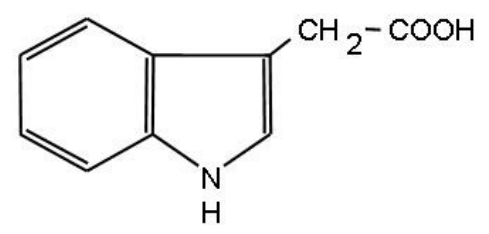

Figura 2. Estrutura do ácido 3-indolil acético (AIA).

A capacidade de produzir AIA é amplamente difundida em bactérias associadas a plantas (PATTEN e GLICK, 1996). O interesse no estudo da produção de AIA em bactérias não deriva apenas dos efeitos fisiológicos que os fitormônios causam em plantas, mas também do possível papel em interações planta-bactéria.

Bactérias cujos genes codificam para enzimas que levam à síntese do fitormônio AIA estão envolvidas em patogênese de plantas ou podem ser responsáveis por promover o crescimento destas (COSTACURTA e VANDERLEYDEN, 1995). Vários destes microorganismos, tais como Agrobacterium tumefaciens, Agrobacterium rhizogenes, Erwinia herbicola e patovars de Pseudomonas syringae (savastanoi e syringae) estão relacionados com patogênese em plantas, ao passo que outros gêneros como Azospirillum, Pseudomonas, Xanthomonas, Rhizobium bem como as espécies Enterobacter cloacae, Acetobacter diazotrophicus e Bradyrhizobium japonicum são reportados como agentes que estimulam o crescimento vegetal (COSTACURTA e VANDERLEYDEN, 1995; PATTEN e GLICK, 1996), contribuindo para o "pool" endógeno de AIA da planta.

Embora seja amplamente aceito que as plantas usam diversas vias para sintetizar AIA, essas vias não estão amplamente caracterizadas no que se refere a enzimas participantes, intermediários e estrutura de genes envolvidos (WOODWARD e BARTEL, 2005). Assim, até o momento, não foi caracterizada uma IPDC em plantas. Supõe-se que esta enzima seja instável e/ou esteja presente em baixas concentrações (KOGA, ADACHI e HIDAKA, 1991a, 1991b,1992). Algumas evidências obtidas com extratos de mudas de Pisum sativum (ervilha) sugerem a existência da via do ácido indolpirúvico [Triptofano $\rightarrow$ Ácido Indolpirúvico $\rightarrow$ Indolacetaldeído $\rightarrow$ Ácido Indolil Acético] (Figura 3) (MOORE e SHANER, 1968). 
A síntese do AIA em bactérias a partir de triptofano pode seguir duas vias principais (Figura 3). Na primeira via, o triptofano sofre transaminação a ácido 3-indol pirúvico, o qual é descarboxilado a 3 -indolacetaldeído e subseqüentemente é transformado em ácido 3-indol acético. Na segunda via, o triptofano é convertido em 3-indolacetamida, que dá origem ao AIA. A segunda via seria preferencial em cepas consideradas patogênicas (YAMADA, 1993; COSTACURTA e VANDERLEYDEN, 1995; PATTEN e GLICK, 1996). Em rizobactérias, os genes para as vias de síntese de AIA são encontrados tanto em plasmídeos como integrados no genoma. 


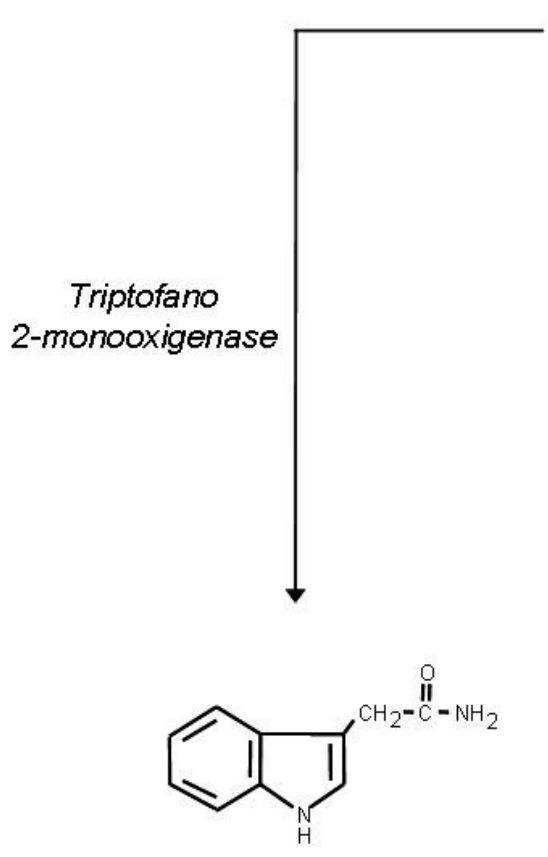

3-Indolacetamida

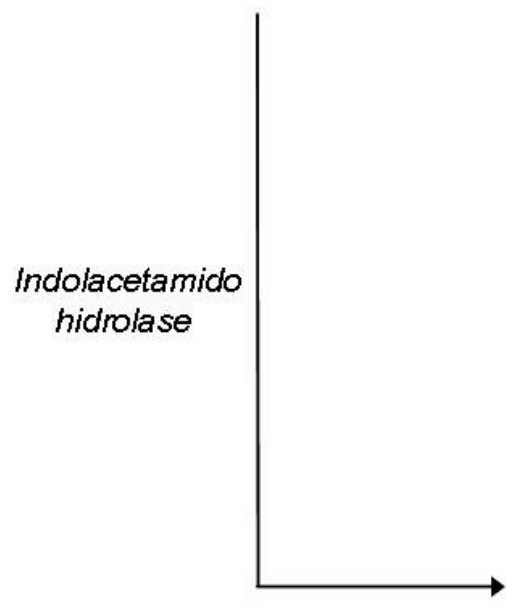<smiles>N[C@H](Cc1c[nH]c2ccccc12)C(=O)O</smiles>

L - Triptofano

Triptofano aminotransferase<smiles>O=C(O)Cc1c[nH]c2ccccc12</smiles>

Ácido 3-Indol Pirúvico

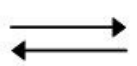<smiles>O=C(O)Cc1c[nH]c2ccccc12</smiles>

Ácido 3-Indolático
Indolpiruvato descarboxilase<smiles>O=CCc1c[nH]c2ccccc12</smiles>

3-Indol Acetaldeído

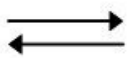<smiles>OCCc1c[nH]c2ccccc12</smiles>

Triptofol Indolacetaldeído oxidase<smiles>O=C(O)Cc1c[nH]c2ccccc12</smiles>

Ácido 3-Indolil Acético (AIA)

Figura 3. Vias de síntese de AIA em bactérias a partir do Triptofano (Adaptado de KOGA, ADACHI e HIDAKA, 1991a). Em itálico encontram-se os nomes das enzimas que catalisam as reações. As setas em negrito indicam a via preferencial em cepas não patogênicas. 
Surge a pergunta: Por que tantas rizobactérias produzem AIA? Uma possibilidade é que estes microorganismos detoxifiquem triptofano e seus análogos por serem compostos que Ihes são deletéreos. AIA também poderia atuar como modulador da produção de cAMP e aminoácidos em bactérias. No entanto, a hipótese mais provável é que a produção deste fitormônio por parte da bactéria estimule a geração de metabólitos na planta, os quais seriam utilizados pelo microorganismo para seu crescimento (PATTEN e GLICK, 1996).

Em resumo, o fato de termos encontrado em $P$. serpens transcritos que apresentam elevada similaridade com seqüências de indolpiruvato descarboxilases (IPDCs) bacterianas é curioso. A coincidência de encontrar o gene IPDC em um tripanossomatídeo que infecta plantas e em bactérias associadas a plantas sugere um processo de transmissão horizontal gênica, como proposto para o gene de isopropil álcool desidrogenase (iPDH) comentado acima (MOLINAS et al., 2003). Outro aspecto tanto ou mais interessante seria compreender qual a vantagem adaptativa para Phytomonas da aquisição de um gene cujo produto estaria relacionado com a síntese do fitormônio AIA. Por analogia com bactérias de plantas, a produção putativa de AIA poderia contribuir para a patogenia ou para estimular o crescimento vegetal. Coincidentemente, foi verificado que Phytomonas spp. podem causar enfermidades devastadoras em plantações de interesse comercial, ao passo que em outras espécies vegetais nenhum dano aparente pode ser monitorado. Estas considerações determinam a importância da realização de estudos centrados no gene IPDC de Phytomonas. 


\section{CONCLUSÕES}

A seqüência do gene da putativa IPDC de $P$. serpens mostrou a presença dos três domínios característicos para ligação à coenzima TPP. A análise da estrutura primária da proteína (seqüência protéica traduzida) indica a possibilidade de formação de uma enzima tetramérica ativa através da ligação com o complexo TPP$\mathrm{Mg}^{2+}$.

Ensaios de PCR mostraram que o gene da putativa IPDC está presente e é bastante conservado em todos os isolados de Phytomonas analisados, e que esta seqüência está ausente em outras espécies de Kinetoplastida (Trypanosoma, Leishmania, Endotrypanum, Crithidia, Blastocrithidia, Herpetomonas e Leptomonas). Isto sugere que a seqüência de IPDC poderia ser um marcador potencial para o gênero Phytomonas.

Concluiu-se que o gene IPDC em $P$. serpens está presente em múltiplas cópias (cerca de $10^{4}$ cópias), organizadas em tandem e separadas por uma região intergênica pequena. As cópias estão concentradas em uma banda cromossômica de aproximadamente 2,1 Mpb. Neste organismo, a seqüência telomérica difere da seqüência conservada em $T$. brucei e $T$. cruzi. Em $P$. françai o número de cópias do gene IPDC é menor (cerca de 200 cópias).

Análises filogenéticas apontam o clado Phytomonas (putativa IPDC) Leishmania (putativa piruvato/indolpiruvato descarboxilase) como grupo-irmão das IPDCs das gama-proteobactérias $P$. agglomerans, E. cloacae, $P$. putida e $E$. carotovora. A proximidade com IPDCs de fitobactérias sugere um processo de transferência horizontal gênica anterior à separação de Phytomonas e Leishmania. Amplificações por PCR com oligonucleotídeos degenerados também sugerem a aquisição desse gene putativo, advindo de um provável ancestral bacteriano, anterior à separação dos tripanossomatídeos do clado que inclui: Leptomonas, Phytomonas, Herpetomonas, Leishmania e Crithidia. 


\section{REFERÊNCIAS *}

ABASCAL, F.; ZARDOYA, R.; POSADA, D. ProtTest: Selection of best-fit models of protein evolution. Bioinformatics, v. 21, p. 2104-2105, 2005.

ALTSCHUL, S. F. et al. Gapped BLAST and PSI-BLAST: a new generation of protein database search programs. Nucleic Acids Res., v. 25, p. 3389-3402, 1997.

ALVAREZ, M. E. et al. The 59-kDa polypeptide constituent of 8-10-nm cytoplasmic filaments in Neurospora crassa is a pyruvate decarboxylase. Gene, v. 130, p. 253258, 1993.

BADENOCH-JONES, J. et al. Phytohormones, Rhizobium mutants, and nodulation in legumes. IV. Auxin metabolites in pea root nodules. J. Plant Growth Regul., v. 3, p. 23-39, Feb., 1984.

BARTEL, B. et al. Inputs to the Active Indole-3-Acetic Acid Pool: De Novo synthesis, Conjugate Hydrolysis, and Indole-3-Butyric Acid $\beta$-Oxidation. J. Plant Growth Regul., v. 20, p. 198-216, 2001.

BATEMAN, A. et al. The Pfam protein families database. Nucleic Acids Res., v. 32, p. D138-141, 2004. Database Issue.

BERRIMAN, M. et al. The genome of the African trypanosome Trypanosoma brucei. Science, v. 309, p. 416-422, Jul. 2005.

BIANCHI, M. M. et al. The 'petite-negative' yeast Kluyveromyces lactis has a single gene expressing pyruvate decarboxylase activity. Mol. Microbiol., v. 19, p. 27-36, 1996.

BOITEUX, A.; HESS, B. Allosteric properties of yeast pyruvate decarboxylase. FEBS Lett., v. 9, p. 293-299, Aug., 1970.

BRANDL, M.; CLARK, E. M.; LINDOW, S. E. Characterization of the indole-3-acetic acid (IAA) biosynthetic pathway in an epiphytic strain of Erwinia herbicola and IAA production in vitro. Can. J. Microbiol., v. 42, p. 586-592, 1996. 
BRANDL, M.; LINDOW, S.E. Cloning and characterization of a locus encoding an indolepyruvate decarboxylase involved in indole-3-acetic acid synthesis in Erwinia herbicola. Appl. Environ. Microb., v. 62, p. 4121-4128, 1996.

BRANDL, M. T.; LINDOW, S. E. Environmental Signals Modulate the Expression of an Indole-3-Acetic Acid Biosynthetic Gene in Erwinia herbicola. Mol. Plant Microbe Interact., v. 10, p. 499-505, 1997.

BRANDL, M. T.; LINDOW, S. E. Contribution of Indole-3-Acetic Acid Production to the Epiphytic Fitness of Erwinia herbicola. Appl. Environ. Microb., 3256-3263, Sept. 1998.

BRANDL, M. T.; QUIÑONES, B.; LINDOW, S. E. Heterogeneous transcription of an indoleacetic acid biosynthetic gene in Erwinia herbicola on plant surface. Proc. Natl. Acad. Sci. USA, v. 98, p. 3454-3459, Mar. 2001.

BRINGAUD, F.; RIVIÈRE, L.; COUSTOU, V. Energy metabolism of trypanosomatids: Adaptation to available carbon sources. Mol. Biochem. Parasitol., v. 149, p. 1-9, 2006.

BRIONES, M. R. S. et al. The evolution of two Trypanosoma cruzi subgroups inferred from rRNA genes can be correlated with the interchange of American mammalian faunas in the Cenozoic and has implications to pathogenicity and host specificity. Mol. Biochem. Parasitol., v. 104, p. 219-232, 1999.

BUCHER, M. et al. Aerobic fermentation in tobacco pollen. Plant Mol. Biol., v. 28, p. 739-750, 1995.

CAMARGO, E. P. Phytomonas and Other Trypanosomatid Parasites of Plants and Fruit. Adv. Parasitol., v. 42, p. 29-112, 1999.

CAMARGO, E. P.; KASTELEIN, P.; ROITMAN, I. Trypanosomatid Parasites of Plants (Phytomonas). Parasitol. Today, v. 6, p. 22-25, 1990.

CANDY, J. M. et al. The role of residues glutamate- 50 and phenylalanine-496 in Zymomonas mobilis pyruvate decarboxylase. Biochem. J., v. 315, p. 745-751, 1996.

CANO, M. I. et al. Molecular karyotype of clone CL Brener chosen for the Trypanosoma cruzi Genome Project. Mol. Biochem. Parasitol., v. 71, p. 273-278, 1995. 
CANO, M. I. N. et al. Electrophoretic Karyotypes and Genome Sizing of the Pathogenic Fungus Paracoccidioides brasiliensis. J. Clin. Microbiol., v. 36, p. $742-$ 747, 1998.

CASTELANI, O.; RIBEIRO, L. V.; FERREIRA, J. F. Differentiation of Trypanosoma cruzi in Culture. J. Protozool., v. 14, p. 447-451, 1967.

CATARINO, L.M. et al. Classification of trypanosomatids from fruits and seeds using morphological, biochemical and molecular markers revealed several genera among fruit isolates. FEMS Microbiol. Lett., v. 201, p. 65-72, 2001.

CAZZULO, J. J. et al. End products and enzyme levels of aerobic glucose fermentation in trypanosomatids. Mol. Biochem. Parasitol., v. 16, p. 329-343, 1985.

CAZZULO, J. J. Aerobic fermentation of glucose by trypanosomatids. FASEB J., v. 6, p. 3153-3161, 1992.

CHAUMONT, F. et al. Aerobic and anaerobic glucose metabolism of Phytomonas sp. isolated from Euphorbia characias. Mol. Biochem. Parasitol., v. 67, p. 321-331, 1994.

CLAVERIE, J. M.; NOTREDAME, C. Bioinformatics for Dummies. New York: Wiley Pub., 2003. 480 p.

COONEY, T. P.; NONHEBEL, H. M. Biosynthesis of indole-3-acetic acid in tomato shoots: measurement, mass-spectral identification and incorporation of ${ }^{2} \mathrm{H}$ from ${ }^{2} \mathrm{H}_{2} \mathrm{O}$ into indole-3-acetic acid, D- and L-tryptophan, indole-3-pyruvate and tryptamine. Planta, v. 184, p. 368-376, 1991.

COSTACURTA, A., KEIJERS, V.; VANDERLEYDEN, J. Molecular cloning and sequence analysis of an Azospirillum brasilense indole-3-pyruvate decarboxylase gene. Mol. Gen. Genet., v. 243, p. 463-472, 1994.

COSTACURTA, A.; VANDERLEYDEN, J. Synthesis of Phytohormones by PlantAssociated Bacteria. Crit. Rev. Microbiol., v. 31, p. 1-18, 1995. Review.

DYDA, F. et al. Catalytic centers in the thiamine diphosphate dependent enzyme pyruvate decarboxylase at 2.4-Á resolution. Biochemistry, v. 32, p. 6165-6170, Jun. 1993. 
DOLLET, M. Plant Diseases Caused by Flagellate Protozoa. Ann. Rev. Phytopathol., v. 22, p. 115-132, 1984.

DOLLET, M. et al. A. 5S ribosomal RNA gene repeat sequences define at least eight groups of plant trypanosomatids (Phytomonas spp.): phloem-restricted pathogens form a distinct section. J. Eukaryot. Microbiol., v. 47, p. 569-574, 2000.

DOLLET, M.; STURM, N. R.; CAMPBELL, D. A. The spliced leader RNA gene array in phloem-restricted plant trypanosomatids (Phytomonas) partitions into two major groupings: epidemiological implications. Parasitology, v. 122, p. 289-297, 2001.

DOLLET, M. et al. A. Kinetoplast DNA minicircles of phloem-restricted Phytomonas associated with diseases of coconut and oil palms have a two-domain structure. FEMS Microbiol. Lett., v. 205, p. 65-69, 2001.

DRUMMOND, A.; STRIMMER, K. PAL: An object-oriented programming library for molecular evolution and phylogenetics. Bioinformatics, v. 17, p. 662-663, 2001.

DUGGLEBY, R. G. Domain Relationships in Thiamine Diphosphate-Dependent Enzymes. Acc. Chem. Res., v. 39, p. 550-557, 2006.

EL-SAYED, N. M. et al. The Genome Sequence of Trypanosoma cruzi, Etiologic Agent of Chagas Disease. Science, v. 309, p. 409-415, Jul. 2005 a.

EL-SAYED, N. M. et al. Comparative Genomics of Trypanosomatid Parasitic Protozoa. Science, v. 309, p. 404-409, Jul. 2005b.

FELSENSTEIN, J. Evolutionary trees from DNA sequences: a maximum likelihood approach. J. Mol. Evol., v. 17, p. 368-376, 1981.

FIORINI, J. E. et al. Morphological, Biochemical and Molecular Characterization of Herpetomonas samuelpessoai camargoi n. subsp., a Trypanosomatid Isolated from the Flower of the Squash Cucurbita moschata. J. Eukaryot. Microbiol., v. 48, p. 6269, 2001.

FITCH, W. M. Toward defining the course of evolution: minimum change for a specific tree topology. Syst. Zool., v. 20, p. 406-416, 1971. 
GASS, N. et al. Pyruvate Decarboxylase Provides Growing Pollen Tubes with a Competitive Advantage in Petunia. Plant Cell, v. 17, p. 2355-2368, 2005.

GONZÁLEZ-HALPHEN, D.; MASLOV, D. A. NADH-ubiquinone oxidoreductase activity in the kinetoplasts of the plant trypanosomatid Phytomonas serpens. Parasitol. Res., v. 92, p. 341-346, 2004.

GRUEN, H. E. Auxins and fungi. Annu. Rev. Plant Physiol., v. 10, p. 405-440, 1959.

GUINDON, S.; GASCUEL, O. A simple, fast, and accurate algorithm to estimate large phylogenies by maximum likelihood. Syst. Biol., v. 52, p. 696-704, 2003.

HALL, T. A. BIOEDIT: a user-friendly biological sequence alignment editor and analysis program for Windows 95/98/NT. Nucleic Acids Symp. Ser., v. 41, p. 95-98, 1999.

HANNAERT, V. et al. Plant-like traits associated with metabolism of Trypanosoma parasites. Proc. Natl. Acad. Sci. USA, v. 100, p. 1067-1071, 2003.

HAWKINS, C. F.; BORGES, A.; PERHAM, R. N. A common structural motif in thiamin pyrophosphate-binding enzymes. FEBS Lett., v. 255, p. 77-82, 1989.

HOLLAR, L.; MASLOV, D. A. A phylogenetic view on the genus Phytomonas. Mol. Biochem. Parasitol., v. 89, p. 295-299, 1997.

HOLLOWAY, P.; SUBDEN, R. E. The isolation and nucleotide sequence of the pyruvate decarboxylase gene from Kluyveromyces marxianus. Curr. Genet., v. 24, p. 274-277, 1993.

HOLLOWAY, P.; SUBDEN, R. E. The nucleotide sequence and initial characterization of pyruvate decarboxylase from the yeast Hanseniaspora uvarum. Yeast, v. 10, p. 1581-1589, 1994.

HOSSAIN, M. A. et al. Characterization of pyruvate decarboxylase genes from rice. Plant Mol. Biol., v. 31, p. 761-770, 1996.

HUGHES, A. L.; PIONTKIVSKA, H. Phylogeny of Trypanosomatidae and Bodonidae (Kinetoplastida) Based on 18S rRNA: Evidence for Paraphyly of Trypanosoma and Six Other Genera. Mol. Biol. Evol., v. 20, p. 644-652, 2003. 
IVENS, A. C. et al. The Genome of the Kinetoplastid Parasite, Leishmania major. Science, v. 309, p. 436-442, Jul. 2005.

JANKEVICIUS, J. V. et al. Ciclo Biológico de Phytomonas. Mem. Inst. Oswaldo Cruz, v. 83, p. 601-610, Nov. 1988. Suppl. 1

JANKEVICIUS, J. V. et al. Life Cycle and Culturing of Phytomonas serpens (Gibbs), a Trypanosomatid Parasite of Tomatoes. J. Protozool., v. 36, p. 265-271, 1989.

JONES, D. T.; TAYLOR, W. R.; THORNTON, J. M. The rapid generation of mutation data matrices from protein sequences. Comp. Appl. Biosci., v. 8, p. 275-282, 1992.

KELLERMANN, E.; SEEBOTH, P. G.; HOLLENBERG, C. P. Analysis of the primary structure and promoter function of a pyruvate decarboxylase gene (PDC1) from Saccharomyces cerevisiae. Nucleic Acids Res., v. 14, p. 8963-8977, 1986.

KELLEY, P. M. et al. Characterization of the maize pyruvate decarboxylase gene. Plant Mol. Biol., v. 17, p. 1259-1261, 1991.

KITAJIMA, E. W.; VAINSTEIN, M. H.; SILVEIRA, J. S. M. Flagellate Protozoon Associated with Poor Development of the Root System of Cassava in the Espírito Santo State, Brazil. Phytopathology, v. 76, p. 638-642, 1986.

KOGA, J.; ADACHI, T.; HIDAKA, H. IAA Biosynthetic Pathway from Tryptophan via Indole-3-pyruvic Acid in Enterobacter cloacae. Agric. Biol. Chem., v. 55, p. 701-706, 1991a.

KOGA, J.; ADACHI, T.; HIDAKA, H. Molecular cloning of the gene for indolepyruvate decarboxylase from Enterobacter cloacae. Mol. Gen. Genet., v. 226, p. 10-16, $1991 b$.

KOGA, J.; ADACHI, T.; HIDAKA, H. Purification and Characterization of Indolepyruvate Decarboxylase: A Novel Enzyme for Indole-3-acetic Acid Biosynthesis in Enterobacter cloacae. J. Biol. Chem., v. 267, p. 15823-15828, Aug., 1992.

KOGA, J. Structure and function of indolepyruvate decarboxylase, a key enzyme in indole-3-acetic acid biosynthesis. Biochim. Biophys. Acta, v. 1249, p. 1-13, 1995. Review. 
LEE, D.W. et al. Cloning and nucleotide sequence of one of the most highly expressed genes, a pdcA homologue of Aspergillus nidulans, in Aspergillus oryzae. Biotechnol. Lett., v. 21, p. 139-142, 1999.

LINDQVIST, Y. et al. Three-dimensional structure of transketolase, a thiamine diphosphate dependent enzyme, at 2.5 Á resolution. EMBO J., v. 11, p. 2373-2379, Jul., 1992.

LOCKINGTON, R. A.; BORLACE, G. N.; KELLY, J. M. Pyruvate decarboxylase and anaerobic survival in Aspergillus nidulans. Gene, v. 191, p. 61-67, 1997.

LU, P.; DAVIS, B. P.; JEFFRIES, T. W. Cloning and characterization of two pyruvate decarboxylase genes from Pichia stipitis CBS 6054. Appl. Environ. Microbiol., v. 64, p. 94-97, 1998.

MAOR, R. et al. In Planta Production of Indole-3-Acetic Acid by Colletotrichum gloeosporioides f. sp. aeschynomene. Appl. Environ. Microbiol., v. 70, p. 18521854, Mar., 2004.

MARCHÉ, S. et al. Characterization and detection of plant trypanosomatids by sequence analysis of the small subunit ribosomal RNA gene. Mol. Biochem. Parasitol., v. 71, p. 15-26, 1995.

MARCHÉ, S. et al. Characterization and detection of plant trypanosomatids by sequence analysis of the small subunit ribosomal RNA gene. Mol. Biochem. Parasitol., v. 71, p. 15-26, 1995.

MASLOV, D. A.; PODLIPAEV, S. A.; LUKEŠ, J. Phylogeny of the Kinetoplastida: Taxonomic Problems and Insights into the Evolution of Parasitism. Mem. Inst. Oswaldo Cruz, v. 96, p. 397-402, April, 2001.

McGHEE, R. B.; COSGROVE, W. B. Biology and Physiology of the Lower Trypanosomatidae. Microbiol. Rev., v. 44, p. 140-173, Mar., 1980.

MIRANDA, K. et al. Acidocalcisomes of Phytomonas françai Possess Distinct Morphological Characteristics and Contain Iron. Microsc. Microanal., v. 10, p. 647655, 2004. 
MOLINAS, S. M. et al. The Multifunctional Isopropyl Alcohol Dehydrogenase of Phytomonas sp. Could be the Result of a Horizontal Gene Transfer from a Bacterium to the Trypanosomatid Lineage. J. Biol. Chem., v. 278, p. 36169-36175, Sept., 2003.

MOLLER, K. et al. Pyruvate decarboxylases from the petite-negative yeast Saccharomyces kluyveri. Mol. Genet. Genomics, v. 270, p. 558-568, 2004.

MOORE, T. C.; SHANER, C. A. Synthesis of Indoleacetic Acid from Tryptophan via Indolepyruvic Acid in Cell-free Extracts of Pea Seedlings. Arch. Biochem. Biophys., v. 127, p. $613-621,1968$.

MOYANO, E. et al. Comparative study between two strawberry pyruvate decarboxylase genes along fruit development and ripening, post-harvest and stress conditions. Plant Sci., v. 166, p. 835-845, 2004.

MUCKE, U. et al. Pyruvate decarboxylase from Pisum sativum. Properties, nucleotide and amino acid sequences. Eur. J. Biochem., v. 237, p. 373-382, 1996.

MULLER, Y. A.; SCHULZ, G. E. Structure of the thiamine- and flavin-dependent enzyme pyruvate oxidase. Science, v. 259, p. 965-967, Feb., 1993.

NAWATHEAN, P.; MASLOV, D. A. The absence of genes for cytochrome $c$ oxidase and reductase subunits in maxicircle kinetoplast DNA of the respiration-deficient plant trypanosomatid Phytomonas serpens. Curr. Genet., v. 38, p. 95-103, 2000.

OPPERDOES, F. R.; MICHELS, P. A. M. Horizontal gene transfer in trypanosomatids. TRENDS Parasitol., v. 23, p. 470-476, 2007.

OZAKI, L. S.; CSEKO, Y. M. T. Genomic DNA cloning and related techniques. In: MOREL, C. M. (Ed.). Genes and Antigens of Parasites: A Laboratory Manual. 2nd ed. Rio de Janeiro: Fundação Oswaldo Cruz, 1984. Cap. 3.4, p. 165-185.

OWEN, C. A. et al. Early induction of alcohol dehydrogenase and pyruvate decarboxylase in cut carnation flowers under hypoxia. Physiol. Plantarum, v. 122, p. 412-418, 2004.

PAGE, R. D. M. TREEVIEW: An application to display phylogenetic trees on personal computers. Comput. Appl. Biosci., v. 12, p. 357-358, 1996. 
PAPPAS, G. J. Jr. et al. Expressed sequence tags from the plant trypanosomatid Phytomonas serpens. Mol. Biochem. Parasitol., v. 142, p. 149-157, 2005.

PATTEN, C. L.; GLICK, B. R. Bacterial biosynthesis of indole-3-acetic acid. Can. J. Microbiol., v. 42, p. 207-220, 1996. Review.

PATTEN, C. L.; GLICK, B. R. Role of Pseudomonas putida Indoleacetic Acid in Development of the Host Plant Root System. Appl. Environ. Microbiol., v. 68, p. 3795-3801, 2002.

PETRY, K. et al. Use of monoclonal antibodies for differentiation of different isolates of Phytomonas (plant trypanosomatids). J. Phytopathol., v. 126, p. 59-68, 1989.

PURVES, W. K. et al. Vida: a ciência da biologia. Tradução de Anapaula Somer Vinagre et al. 6a ed. Porto Alegre: Artmed, 2002. 1126 p.

RAJ, K. C. et al. Cloning and Characterization of the Zymobacter palmae Pyruvate Decarboxylase Gene (pdc) and Comparison to Bacterial Homologues. Appl. Environ. Microbiol., v. 68, p. 2869-2876, 2002.

REEVES, J. H. Heterogeneity in the substitution process of amino acid proteins coded for by mitochondrial DNA. J. Mol. Evol., v. 35, p. 17-31, 1992.

RIOU, J. F. et al. Characterization of Phytomonas sp. kinetoplast DNA: a plant pathogenic trypanosomal species. FEBS Lett., v. 213, p. 304-308, 1987.

SAITOU, N.; NEI, M. The neighbor-joining method: a new method for reconstructing phylogenetic trees. Mol. Biol. Evol., v. 4, p. 406-425, 1987.

SAMBROOK, J.; RUSSELL, D. W. Molecular Cloning: A Laboratory Manual. 3. ed. New York: Cold Spring Harbor, 2001.

SÁNCHEZ-MORENO, M. et al. Characterization of carbohydrate metabolism and demonstration of glycosomes in a Phytomonas sp. isolated from Euphorbia characias. Mol. Biochem. Parasitol., v. 54, p. 185-199, 1992. 
SÁNCHEZ-MORENO, M. et al. Isolation, in vitro culture, ultrastructure study, and characterization by lectin-agglutination tests of Phytomonas isolated from tomatoes (Lycopersicon esculentum) and cherimoyas (Anona cherimolia) in southeastern Spain. Parasitol. Res., v. 81, p. 575-581, 1995.

SANCHIS, V. et al. A pyruvate decarboxylase gene from Aspergillus parasiticus. FEMS Microbiol. Lett., v. 117, p. 207-210, 1994.

SBRAVATE, C. et al. Culture and Generic Identification of Trypanosomatids of Phytophagous Hemiptera in Brazil. J. Protozool., v. 36, p. 543-547, 1989.

SCHÜTZ, A. et al. Crystal structure of thiamindiphosphate-dependent indolepyruvate decarboxylase from Enterobacter cloacae, an enzyme involved in the biosynthesis of the plant hormone indole-3-acetic acid. Eur. J. Biochem., v. 270, p. 2312-2321, 2003.

SERRANO, M. G. et al. Trypanosomatidae: Phytomonas Detection in Plants and Phytophagous Insects by PCR Amplification of a Genus-Specific Sequence of the Spliced Leader Gene. Exp. Parasitol., v. 91, p. 268-279, 1999.

SERRANO, M. G. Taxonomia e Filogenia Molecular de Phytomonas. 174 f. Tese (Doutorado em Parasitologia) - Instituto de Ciências Biomédicas, Universidade de São Paulo, São Paulo, 2000.

SHELDRAKE, A. R. The Production of Hormones in Higher Plants. Biol. Res., v. 48, p. 509-559, 1973.

SHIAO, T. L. et al. Overexpression of Alcohol Dehydrogenase or Pyruvate Decarboxylase Improves Growth of Hairy Roots at Reduced Oxygen Concentrations. Biotechnol. Bioeng., v. 77, p. 455-461, 2002.

SKORY, C. D. Induction of Rhizopus oryzae Pyruvate Decarboxylase Genes. Curr. Microbiol., v. 47, p. 59-64, 2003.

SPAEPEN, S. et al. Characterization of Phenylpyruvate Decarboxylase, Involved in Auxin Production of Azospirillum brasilense. J. Bacteriol., v. 189, p. 7626-7633, 2007.

SWOFFORD, D. L. PAUP*. Phylogenetic Analysis Using Parsimony ("and Other Methods). Version 4. Sunderland: Sinauer Associates, 2002. 
TAM, Y. Y.; NORMANLY, J. Determination of indole-3-pyruvic acid levels in Arabidopsis thaliana by gas chromatography-selected ion monitoring-mass spectrometry. J. Chromatogr. A, v. 800, p. 101-108, 1998.

TEIXEIRA, M. M. G.; CAMARGO, E. P. Monoclonal Antibodies for the Identification of Trypanosomatids of the Genus Phytomonas. J. Protozool., v. 36, p. 262-264, 1989.

TEIXEIRA M. M. et al. Trypanosomatidae: a spliced-leader-derived probe specific for the genus Phytomonas. Exp. Parasitol., v. 84, p. 311-319, 1996.

THOMPSON, J. D.; HIGGINS, D. G.; GIBSON, T. J. CLUSTAL W : improving the sensitivity of progressive multiple sequence alignment through sequence weighting, positions - specific gap penalties and weight matrix choice. Nucleic Acids Res., v. 22, p. 4673-4680, 1994.

TIELENS, A. G. M.; VAN HELLEMOND, J. J. Differences in Energy Metabolism Between Trypanosomatidae. Parasitol. Today, v. 14, p. 265-271, 1998.

TSOU, A. Y. et al. Mandelate pathway of Pseudomonas putida: sequence relationships involving mandelate racemase, (S)-mandelate dehydrogenase, and benzoylformate decarboxylase and expression of benzoylformate decarboxylase in Escherichia coli. Biochemistry, v. 29, p. 9856-9862, 1990.

UTTARO, A. D.; SÁNCHEZ-MORENO, M.; OPPERDOES, F. R. Genus-specific biochemical markers for Phytomonas spp. Mol. Biochem. Parasitol., v. 90, p. 337342, 1997.

VAINSTEIN, M. H.; ROITMAN, I. Cultivation of Phytomonas françai Associated with Poor Development of Root System of Cassava. J. Protozool., v. 33, p. 511-513, 1986.

VAN DER PLOEG, L. H. T.; LIU, A. Y. C.; BORST, P. Structure of the growing telomeres of trypanosomes. Cell, v. 36, p. 459-468, Feb., 1984.

VARGAS, N. et al. Amplification of a Specific Repetitive DNA Sequence for Trypanosoma rangeli Identification and Its Potential Application in Epidemiological Investigations. Exp. Parasitol., v. 96, p. 147-159, 2000. 
VARGAS, N.; PEDROSO, A.; ZINGALES, B. Chromosomal polymorphism, gene synteny and genome size in $T$. cruzi I and T. cruzi II groups. Mol. Biochem. Parasitol., v. 138, p. 131-141, 2004.

VICKERMAN, K. The evolutionary expansion of the Trypanosomatid Flagellates. Int. J. Parasitol., v. 24, p. 1317-1331, 1994.

WALLER, R. F.; MCCONVILLE, M. J.; MCFADDEN, G. I. More plastids in human parasites? TRENDS Parasitol., v. 20, p. 54-57, 2004.

WANG, Q. et al. Purification, characterization, cloning and expression of pyruvate decarboxylase from Torulopsis glabrata IFO005. J. Biochem., v. 136, p. 447-455, 2004.

WOODWARD, A. W.; BARTEL, B. Auxin: Regulation, Action and Interaction. Ann. Bot., v. 95, p. 707-735, 2005.

YAGI, K. et al. Evidence for the presence of DNA-binding proteins involved in regulation of the gene expression of indole-3-pyruvic acid decarboxylase, a key enzyme in indole-3-acetic acid biosynthesis in Azospirillum lipoferum FS. Biosci. Biotechnol. Biochem., v. 65, p. 1265-1269, 2001.

YAMADA, T. The role of auxin in plant-disease development. Annu. Rev. Phytopathol., v. 31, p. 253-273, 1993.

YANG, Z. Maximum-likelihood estimation of phylogeny from DNA sequences when substitution rates differ over sites. Mol. Biol. Evol., v. 10, p. 1396-1401, 1993. 